\title{
Development and Finishing Technology of Waterborne UV Lacquer-Coated Wooden Flooring
}

\author{
Zinan Zhao, ${ }^{a}$ Yiting Niu, ${ }^{b}$ and Fengyi Chen ${ }^{a, *}$ \\ To develop a waterborne wooden flooring coating, the existing problems \\ of the current waterborne coated wooden floorings were analyzed, and \\ their corresponding solutions were considered. In this paper, based on the \\ final effects of a novel waterborne UV wooden floor coating, the authors \\ used a waterborne UV coating with different solids contents, as well as \\ finishing and drying technology to treat the substrate with different tree \\ species. According to the LY/T standard 1859-2009 (2009) and Q/YFL \\ standard 0035-2018 (2018), the performance of the varnish film of the \\ waterborne UV wooden floor coating was determined. The waterborne \\ coating wooden flooring processes and effects of the varnish film were \\ optimized to provide excellent performance. The performance of the \\ varnish film and the developed waterborne coated wooden flooring met \\ the standard requirements: the surface wear-resistance was less than or \\ equal to $0.15 \mathrm{~g} / 100 \mathrm{r}$, the varnish film hardness was greater than or equal \\ to $\mathrm{H}$, the level of varnish film adhesion was less than or equal to 2 , and the \\ total volatile organic compounds was less than or equal to $20 \mu \mathrm{g} / \mathrm{m}^{3}$. This \\ study provided a demonstration and basis for wooden flooring companies \\ to develop a waterborne wooden floor coating.
}

Keywords: Waterborne UV coatings; Wooden flooring; Finishing technology; Drying technology; Varnish film performance

Contact information: a: Langfang Huari Furniture Co., Ltd., Langfang 065000 China; b: Co-Innovation Center of Efficient Processing and Utilization of Forest Resources, Nanjing Forestry University, Nanjing 210037, China;

*Corresponding author: chenfengyi423@163.com

\section{INTRODUCTION}

In recent years, the Chinese and local governments have been advocating for advances in environmental protection, issuing multiple environmental protection policies and improving the standards for volatile organic compounds (VOC) limits for coating materials and promoting pollution treatments to reduce the environmental pollution and improve the living quality (Xiong et al. 2018b; Eva et al. 2020; Xiong et al. 2020). In 2017, the Chinese national standard GB/T 35601-2017 (2017), issued by the General Administration of Quality Supervision and Standardization Administration of the People's Republic of China, clearly stipulated that the use of waterborne coatings was a necessary condition for wooden flooring products to become green products (Feng et al. 2020; Challener 2015). Meanwhile, with an increase in consumption levels of the individual, high-quality and environmentally friendly wooden floorings will become the primary consumption product. The development of waterborne coated wooden flooring and the application of waterborne coatings on wooden flooring are imminent (Tang et al. 2003; Zhu et al. 2016; Xiong and Wu 2018). 
Waterborne varnish refers to a coating that uses water as the dispersion medium or solvent, and the film-forming materials are dissolved or dispersed in the water (Yan et al. 2020a). Different from the traditional solvent-borne paint, the biggest advantage of using a waterborne coating is that more than $80 \%$ of VOC and other harmful substances, e.g., formaldehyde, benzene, and xylene, found in the coating can be eliminated. Currently, the application of waterborne coatings on furniture and wooden doors is relatively established (Lin et al. 2019; Panek et al. 2019). However, because the surface performance (hardness and wear resistance) of wooden flooring is greater than that of wooden furniture, waterborne coating technology presently cannot meet the requirements needed for manufacturing wooden flooring. Therefore, the application of waterborne coatings to flooring still needs to overcome many problems (Spilman et al. 2018; Cai et al. 2020; Yan et al. 2020b). These problems include: how to promote the transformation of the flooring industry from being resource and energy intensive to resource saving and environment friendly, and to promote green production and green consumption as an inevitable choice for the flooring industry (Xiong et al. 2017; Tao et al. 2019). The use of waterborne coatings to manufacture wooden floors can eliminate the VOC emissions from wooden floor coating materials at the source and provide a new option for flooring companies to transform and upgrade, improving product quality and increasing profitability. The application of waterborne coating materials can meet the requirements needed for green and sustainable development at home and abroad (Xiong et al. 2018a; Xu et al. 2020).

Several past studies have considered the waterborne coating of wooden flooring. Hwang et al. (2009) studied the effect of the drying temperature and time of waterborne UV-curable coating in flash-off step on the surface morphology of varnish film. The results showed that insufficient drying can cause defects, e.g., bubbles and peeling, on the surface of varnish film. Sufficient drying not only can ensure a high-quality appearance, but also it can enhance the performance of the varnish film. Bongiovanni et al. (2002) used UVcurable coating with additives containing fluorine to coat the surface of wood materials, and the properties of varnish film, e.g., glossiness, adhesion, hardness, etc., were tested. The results showed that the varnish film formed from the coating with additives containing fluorine had a greater performance in terms of surface glossiness and chemical resistance. Wu et al. (2019) coated the wood materials with novel a waterborne UV coating and studied the effects of the coating weight on the drying time and performance of the varnish film. The results showed that with an increase in the weight of the waterborne coating, the longer was the drying time of the varnish film and the longer was the forming time of the varnish film. When the thickness of the varnish film was $60 \mu \mathrm{m}$, the drying time was 4 min, the hardness was $2 \mathrm{H}$, and the level of adhesion was 2, which met the requirements of Chinese national standard GB/T 18103-2013 (2013). Li and Shu (2007) coated a wooden flooring substrate with a waterborne UV coating with different compositions and ratios, and the transmittance index of the varnish film was compared and analyzed. The results showed that there was a greater effect of coating with different ratios on the grain and color distinctness of image (DOI). By consulting and analyzing the existing literature, it is not difficult to find that the studies on waterborne coating wooden flooring focuses on the influence of waterborne coating in terms of appearance and performance. However, there have been few studies on the effects of finishing technology and process, or the function of the waterborne coating on the hardness, wear resistance, etc.

During the research on waterborne coated wooden flooring, it was found that the physical and chemical properties of the surface, especially the hardness and surface wear resistance, were strongly affected by the application of waterborne UV coating on wooden 
flooring. First, due to the low solids content of water-based coating, the varnish film is relatively thin, and the filling effect of the low-density wood used for floor production is poor, resulting in low hardness and poor wear resistance of the floor varnish film (Shen et al. 2010; Huang et al. 2018; Li et al. 2018). Second, due to the need for dewatering treatment in the production process of waterborne coated wooden flooring, the production efficiency of waterborne coating for wooden flooring is extremely low (Yan et al. 2019). Third, due to the high moisture content of the blanks used for the production floor, the poor dimensional stability of the tree species, and the poor sealing properties of the waterborne coating, the stability of the floor in the width direction of the waterborne coating is poor, and it is prone to reduce the size of the width direction and increase the gap between adjacent wooden flooring pieces (Li et al. 2019; Sun et al. 2020).

In this study, the authors developed and applied a novel waterborne coating to wooden flooring products in combination with the finishing technology of wooden flooring and the performance requirements of varnish film. Through the optimization of tree species, waterborne coating formulations, and finishing technology adjustments, this study focused on solving the physical and chemical performance problems of the surface varnish film hardness and wear resistance of waterborne UV coated wooden flooring. This achievement not only expands the range of wooden floor coatings, but also provides a basis and data support for the research and development of waterborne coated wooden flooring.

\section{EXPERIMENTAL}

\section{Materials}

Wooden flooring substrate

The various wood species used were oak, toothed oak, Robinia, walnut, elm, pinnate pometia, and Newtonia spp. The size of the samples was $910 \mathrm{~mm} \times 122 \mathrm{~mm} \times 18$ $\mathrm{mm}$, and the materials were purchased from Xifeng County Senhai Wood Industry Co., Ltd. (Tieling, China).

\section{Waterborne UV coatings}

A: The waterborne UV coating was purchased from Shandong Penglai Luyuan Paint Industry Co., Ltd. (Penglai, China), which included primers and a topcoat, and the primers and topcoat were classified as varnish. The primers include a waterborne UV colored primer, a waterborne UV transparent primer, and a waterborne UV functional primer, with solid contents of $6.4 \%, 42.6 \%$, and $40.0 \%$, respectively, which were all white emulsions and dispersible in water. The topcoat was a waterborne UV matte topcoat with a solid content $41.1 \%$, which was white emulsion and mixed in water, with a glossiness of level 2.

B: The waterborne UV coating was purchased from Shandong Penglai Luyuan Paint Industry Co., Ltd. (Penglai, China), which included primers and a topcoat, and the primers and topcoat were types of varnish. The primers included a waterborne UV colored primer, a waterborne UV filled primer, and a waterborne UV transparent primer, with solid contents of $6.9 \%, 60.7 \%$, and $60.4 \%$, respectively, which were all white emulsions. The topcoat was a waterborne matte topcoat with a solid content of $48.7 \%$, which was white emulsion and dispersible in water, with a glossiness of level 2.

C: The waterborne UV coating was purchased from Guangdong Hongfang Paint Co., Ltd. (Huizhou, China), which included primers and a topcoat, and the primers and 
topcoat were varnish products. The primers include a waterborne UV colored primer, a waterborne UV high-definition primer, and a waterborne UV sanding primer, with solid contents of $7.3 \%, 98 \%$, and $98 \%$, respectively, which were all white emulsion. The topcoat was a waterborne UV matte topcoat with a solid content of $98 \%$, which was a light yellow liquid and dispersible in water.

\section{Experimental Instruments}

The following instruments were used: Coating machine (Xiamen Maosen Automation Equipment Co. Ltd., Xiamen, China); humidity and temperature control (Shenzhen Changxu Machinery Equipment Co. Ltd., Shenzhen, China); electric thermostat blast oven (Chengdu Shengjie Technology Co. Ltd., Chengdu, China); infrared drying equipment (Suzhou Green Painting Technology Co. Ltd., Suzhou, China); UV-curing equipment (Dongguan Jingyu Environmental Testing Equipment Co., Ltd., Dongguan, China); varnish film multi-purpose detector (Shanghai Meiyu Instrument Equipment Co. Ltd., Shanghai, China); rolling wear teat machine (Shandong Zhongyi Instrument Co. Ltd., Jinan, China); and electronic balance (Shanghai Sunny Hengping Scientific Instrument Co. Ltd., Shanghai, China), which had a measuring accuracy of $0.1 \mathrm{mg}$ and a measuring range of $0 \mathrm{~g}$ to $220 \mathrm{~g}$.

\section{Experimental Principles and Methods}

Selection of tree species and optimization of water content

Tree species screening: First, as the raw materials for wooden flooring, tree species with a high density and dimensional stability not only can make up for poor waterborne coating performance, but also highlight the grain and visual characteristics of wood itself. In addition, it can achieve the aesthetic effect of "seeing the wood but not the coating" (Wilfried et al. 2004). Second, it is necessary to select different species as the substrate for the experiment since the different finishing technologies and effects have different requirements.

Optimization of water content: After finishing the waterborne coating process, the moisture content of the treated wood will increase by $1 \%$ to $2 \%$, and the increase of moisture content will cause the reduced scale and gap of the waterborne coated wooden flooring after a period of time. Therefore, before finishing, the moisture content of the blank of waterborne coated wooden flooring should be balanced and cured to ensure product quality. The moisture content of walnut, oak, Robinia, and toothed oak was controlled at $8 \%$ to $12 \%$. The moisture content of elm, pinnate pometia, and Newtonia spp. was controlled at $9 \%$ to $13 \%$.

\section{Process of Finishing Technology}

Opening effect of waterborne coating A

Comprised of a waterborne UV primer and a waterborne UV topcoat, the waterborne UV coating A was used for experimental research and analysis with three different finishing technological processes.

Process 1: The finishing process included 5 primer and 2 topcoat layers, and the UV-curing was carried out directly after each coating was finished, the time of UV-curing was $6 \mathrm{~s}$, and the irradiation energy of UV-curing was 230 to $260 \mathrm{~mJ} / \mathrm{cm}^{2}$. The wet coating weight of each primer was $8 \mathrm{~g} / \mathrm{m}^{2}$ to $10 \mathrm{~g} / \mathrm{m}^{2}$, and the wet coating weight of each topcoat was $5 \mathrm{~g} / \mathrm{m}^{2}$. The process flow is shown in Fig. 1 . 


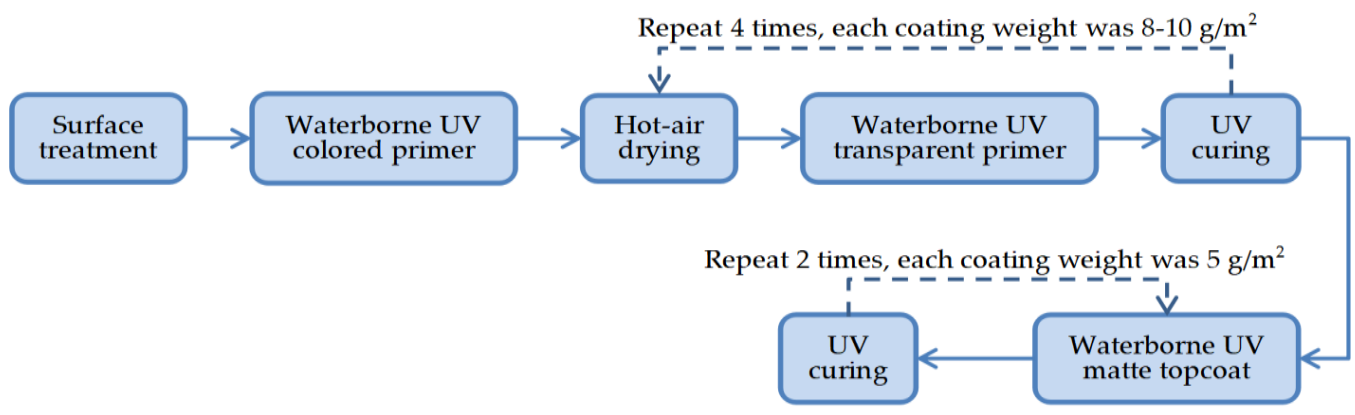

Fig. 1. The process of opening finishing for waterborne coating A (process 1 and 2 )

Process 2: Based on Process 1, the total number of finishing applications of the primer was increased from 5 to 8 . The coating weight of each primer and topcoat was same as in Process 1. The UV-curing time and irradiation energy of the last waterborne UV transparent primer was $6 \mathrm{~s}$ and 135 to $160 \mathrm{~mJ} / \mathrm{cm}^{2}$, and the irradiation energy of the first and second waterborne UV matte topcoat was 190 to $220 \mathrm{~mJ} / \mathrm{cm}^{2}$ and 510 to $550 \mathrm{~mJ} / \mathrm{cm}^{2}$.

Process 3: The finishing process was 8 primer and 2 topcoat layers and 10-meter infrared drying was carried out after each primer application, at a temperature of $80{ }^{\circ} \mathrm{C}$ and a drying time of $28 \mathrm{~s}$. The UV-curing was carried out after the infrared drying. The process flow is shown in Fig. 2.

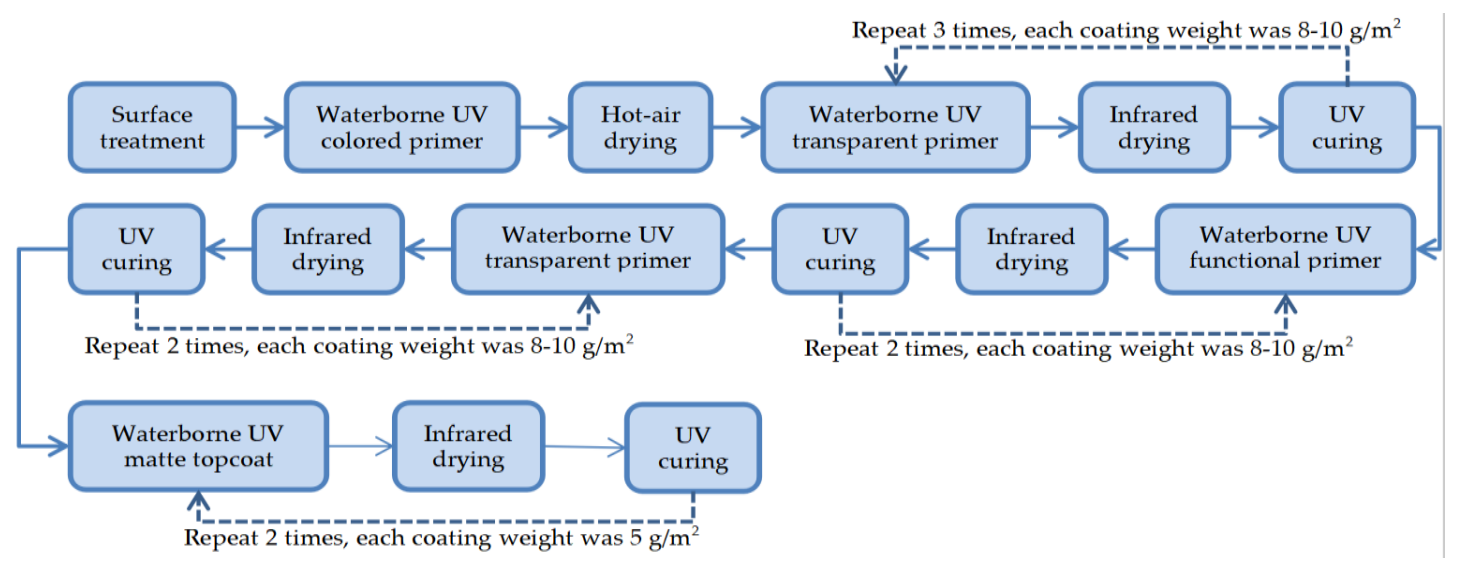

Fig. 2. The process of opening finishing for waterborne coating A (process 3 )

\section{Closed effect of waterborne coating $B$}

Comprised of a waterborne UV primer and a waterborne UV topcoat, the waterborne UV coating B was used for experimental research and analysis with four different finishing technological processes. The wood pores were completely filled with waterborne UV filled primer. The hardness, fullness, and contamination resistance properties of the varnish film were ensured via the usage of a waterborne UV transparent primer and waterborne UV matte topcoat. The wet coating weight of each primer was 8 $\mathrm{g} / \mathrm{m}^{2}$ to $10 \mathrm{~g} / \mathrm{m}^{2}$, and the wet coating weight of each topcoat was $5 \mathrm{~g} / \mathrm{m}^{2}$.

Process 1: The finishing technology was twin-roll, with 8 primer and 2 topcoat layers and 10 meter infrared drying was carried out after each primer and topcoat application, at a temperature of $80^{\circ} \mathrm{C}$ and a drying time of $28 \mathrm{~s}$. The UV-curing was carried out after the infrared drying. The process flow is shown in Fig. 3. 


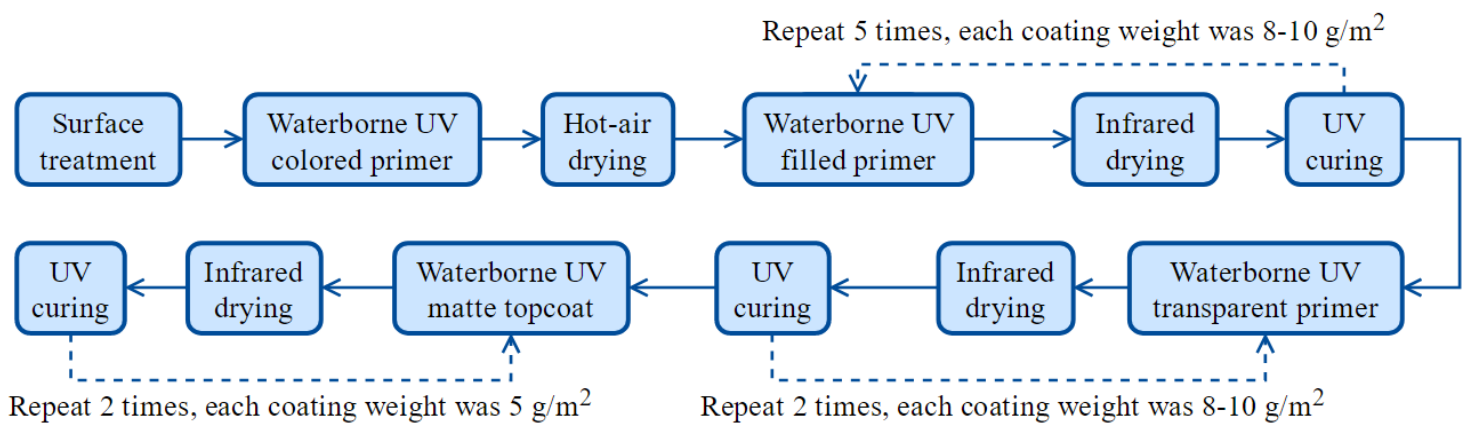

Fig. 3. The process of closed finishing for waterborne coating B (process 1 and 3 )

Process 2: The finishing technology was twin-roll, with 8 primer and 2 topcoat layers . There was no hot-air and infrared drying after finishing; the coating was cured directly. The process flow is shown in Fig. 4.

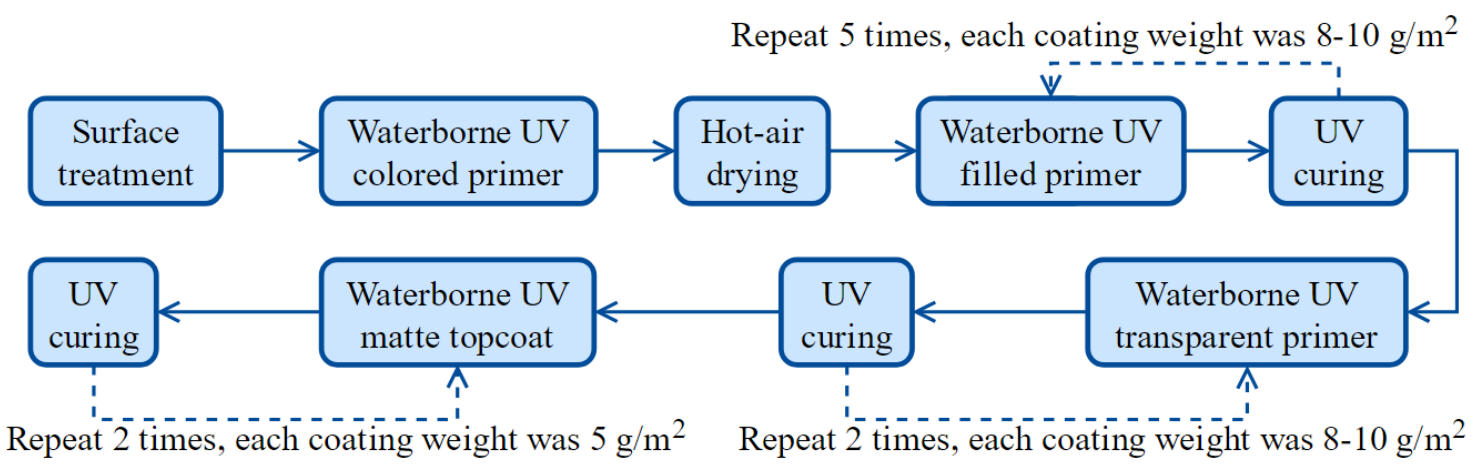

Fig. 4. The process of closed finishing for waterborne coating B (process 2 and 4)

Process 3: Changed the twin-roll finishing in Process 1 to single-roll, and the rest of the process and parameters were not changed.

Process 4. Changed the twin-roll finishing in Process 2 to single-roll, and the rest of the process and parameters were not changed.

\section{Closed effect of waterborne coating $C$}

Comprised of a waterborne UV primer and waterborne UV topcoat, the waterborne UV coating $\mathrm{C}$ was used for experimental research and analysis with three different finishing technological processes.

Process 1: Finishing the wooden substrate in the following order: waterborne UV colored primer, waterborne UV high-definition primer, waterborne UV sanding primer, waterborne UV high-definition primer, and waterborne UV matte topcoat. The wet coating weight of each primer was 11 to $13 \mathrm{~g} / \mathrm{m}^{2}$, and the wet coating weight of each topcoat was 5 to $6 \mathrm{~g} / \mathrm{m}^{2}$.

The UV-curing irradiation energy of each waterborne UV coating is shown in Table 1. After waterborne UV high-definition primer was finished, one interlayer sanding was carried out by sanding machine with 400 mesh sandpaper after the UV-curing of each two coatings, and the process flow is shown in Fig. 5. 


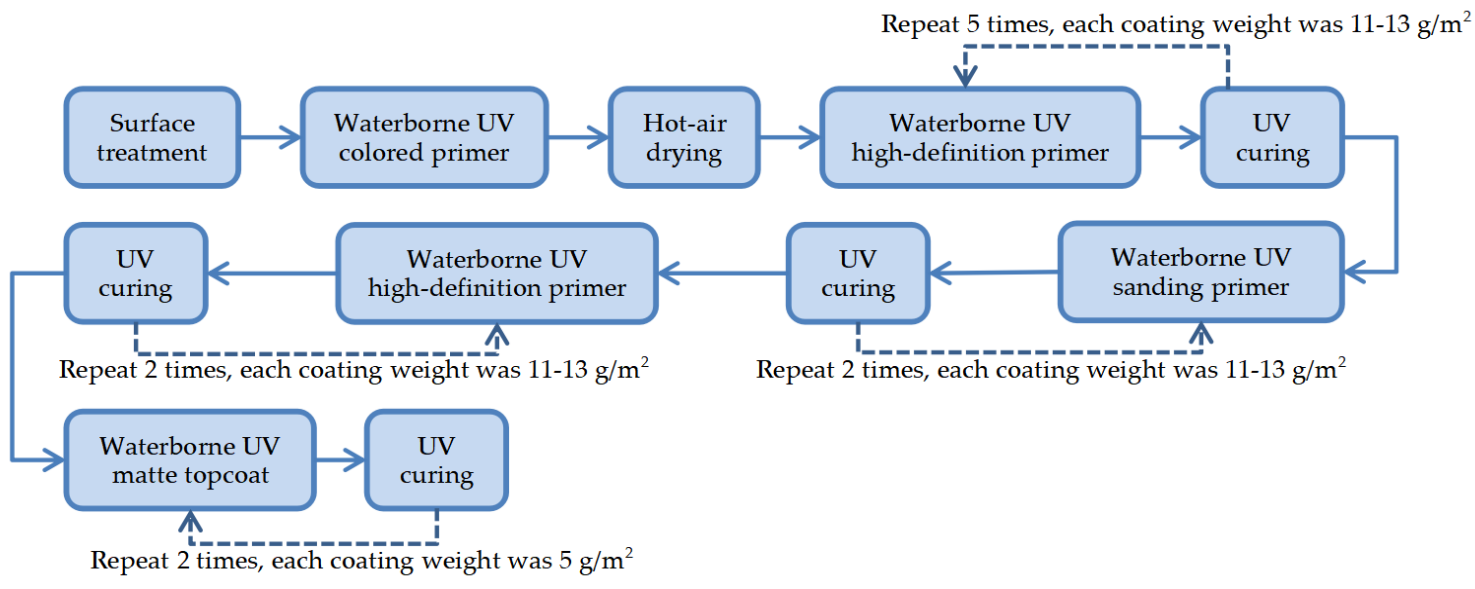

Fig. 5. The process of closed finishing waterborne coating $C$ (process 1,2 and 3 )

Table 1. UV-curing Parameters of Different Coatings

\begin{tabular}{|c|c|c|}
\hline Number & Types of waterborne UV coating & Irradiation energy $\left(\mathrm{mJ} / \mathrm{cm}^{2}\right)$ \\
\hline 1 & \multirow{2}{*}{ Waterborne UV high-definition primer } & $61 \mathrm{~mJ} / \mathrm{cm}^{2}$ \\
\hline 2 & & $85 \mathrm{~mJ} / \mathrm{cm}^{2}$ \\
\hline 3 & Waterborne UV sanding primer & $55 \mathrm{~mJ} / \mathrm{cm}^{2}$ \\
\hline 4 & \multirow{3}{*}{ Waterborne UV high-definition primer } & $85 \mathrm{~mJ} / \mathrm{cm}^{2}$ \\
\hline 5 & & $97 \mathrm{~mJ} / \mathrm{cm}^{2}$ \\
\hline 6 & & $166 \mathrm{~mJ} / \mathrm{cm}^{2}$ \\
\hline 7 & \multirow{2}{*}{ Waterborne UV matte topcoat } & $73 \mathrm{~mJ} / \mathrm{cm}^{2}$ \\
\hline 8 & & $461 \mathrm{~mJ} / \mathrm{cm}^{2}$ \\
\hline
\end{tabular}

Process 2: Based on Process 1, the waterborne UV high-definition primer after the waterborne UV colored primer was replaced with a waterborne UV harden primer. The other processes and parameters were not changed.

Process 3: Based on Process 1, the waterborne UV sanding primer after the waterborne UV colored primer was replaced with a waterborne UV harden primer. The other processes and parameters were not changed.

\section{Performance Test of Varnish Film}

According to LY/T standard 1859-2009 (2009) and Q/YFL standard 0035-2018 (2018), the varnish film adhesion, surface wear resistance, and hardness of the wooden floorings with different waterborne UV coating and finishing technology were tested, and the test results were summarized and analyzed.

Based on the test results, the waterborne UV coating and finishing technology with the greatest performing varnish film were selected for both the opening and closed effects. The waterborne coated wooden flooring produced with the best finishing processes will be tested and evaluated by a third-party institution. 


\section{RESULTS AND DISCUSSION}

\section{Screening Results of Tree Species}

Opening finishing process: Because there was no pore filling, the mostly thin coats are able to fully express the natural grain of the wood; however, it weakened certain characteristics, i.e., the low hardness and poor filling property of low solid content waterborne varnish film. Based on this, the species of oak, elm, and pinnate pometia were used as substrate in the experiment of waterborne UV coating A.

Closed finishing process: Through the use of a thin finishing process using waterborne coating, tree species with high hardness, clear wood grain, and bright colors were selected to be finished with a waterborne coating with high solid content, so the natural color of the wood could be fully retained. Therefore, the pinnate pometia, Newtonia spp., and oak were as the substrates in the experiment for waterborne UV coating B, and toothed oak, Robinia, and walnut were as the substrates in the experiment for waterborne UV coating $C$.

\section{Results and Analysis of Finishing Technology}

Opening effect of waterborne coating A

According to Process 1 for waterborne coating A, the wooden flooring substrate of (fiber drawing, distressed) oak, elm, and pinnate pometia were finished, and the varnish film was tested. The test results showed that the varnish film adhesion of the wooden flooring meet the level 1 standards; the surface wear resistance was $0.06 \mathrm{~g} / 100 \mathrm{r}$ to 0.08 $\mathrm{g} / 100 \mathrm{r}$ and the $48 \mathrm{~h}$ varnish film hardness was 5B to 3B.

Through the analysis of the test results, the varnish film adhesion and surface wear resistance of the wooden flooring substrate finished via Process 1 met the standard requirements. However, the varnish film hardness and wear resistance were not enough to meet the production requirements. In order to solve this problem, the substrates were finished according to Process 2 (waterborne coating A) and testing the hardness and wear resistance of the resulting varnish film. The results were summarized in Table 2.

Table 2. Performance of the Varnish Film on Different Wood Species

\begin{tabular}{|c|c|c|c|c|c|}
\hline \multirow{2}{*}{ Species } & \multirow{2}{*}{ Surface Treatment } & $\begin{array}{c}\text { Surface Wear Resistance } \\
(\mathrm{g} / 10 \mathrm{r})\end{array}$ & \multicolumn{3}{|c|}{$\begin{array}{c}\text { Varnish Film } \\
\text { Hardness }\end{array}$} \\
\cline { 4 - 6 } & & & $48 \mathrm{~h}$ & $15 \mathrm{~d}$ & $30 \mathrm{~d}$ \\
\hline Oak & Fiber drawing & 0.1 & $3 \mathrm{~B}$ & $2 \mathrm{~B}$ & $\mathrm{~B}$ \\
\hline Oak & Distressed & 0.14 & $4 \mathrm{~B}$ & $3 \mathrm{~B}$ & $\mathrm{H}$ \\
\hline Elm & - & 0.15 & $5 \mathrm{~B}$ & $3 \mathrm{~B}$ & $\mathrm{HB}$ \\
\hline Pinnate pometia & - & 0.11 & $5 \mathrm{~B}$ & $2 \mathrm{~B}$ & $\mathrm{~B}$ \\
\hline
\end{tabular}

When the total applications of the waterborne UV primer was increased to 8 , the thickness of the varnish film increased and the surface wear resistance was increased from $0.06 \mathrm{~g} / 100 \mathrm{r}$ to $0.08 \mathrm{~g} / 100 \mathrm{r}$ to $0.10 \mathrm{~g} / 100 \mathrm{r}$ to $0.15 \mathrm{~g} / 100 \mathrm{r}$, which meet the standard requirements. The test results of the $48 \mathrm{~h}$ varnish film hardness was $5 \mathrm{~B}$ to $3 \mathrm{~B}$. As the standing time increased, the hardness of the varnish film increased. When the standing time was increased to $30 \mathrm{~d}$, the hardness increased from $\mathrm{B}$ to $\mathrm{H}$. The reason for this increase was that the water in the varnish film was volatilized; therefore, the hardness was improved as the standing time increased. Therefore, to enhance the hardness of the varnish film, infrared drying was added, according to the process and parameters of Process 3 (waterborne coating A). The hardness of the varnish film was tested, as shown in Table 3. 
Table 3. Varnish Film Hardness for Different Wood Species Depending on the Standing Time

\begin{tabular}{|c|c|c|c|c|}
\hline \multirow{2}{*}{ Species } & \multirow{2}{*}{ Surface Treatment } & \multicolumn{3}{|c|}{ Varnish Film Hardness } \\
\cline { 3 - 5 } & & $48 \mathrm{~h}$ & $15 \mathrm{~d}$ & $30 \mathrm{~d}$ \\
\hline Oak & Fiber drawing & $\mathrm{B}$ & $\mathrm{B}$ & $\mathrm{H}$ \\
\hline Oak & Distressed & $2 \mathrm{~B}$ & $\mathrm{~B}$ & $\mathrm{~B}$ \\
\hline Elm & - & $\mathrm{B}$ & $\mathrm{H}$ & $2 \mathrm{H}$ \\
\hline Pinnate pometia & - & $\mathrm{B}$ & $\mathrm{H}$ & $\mathrm{H}$ \\
\hline
\end{tabular}

The $48 \mathrm{~h}$ varnish film hardness increased from $5 \mathrm{~B}$ to $3 \mathrm{~B}$ to $2 \mathrm{~B}$ to $\mathrm{B}$ after adding the infrared drying. At the same time, the longer the standing time, the better the hardness of varnish film; the $30 \mathrm{~d}$ varnish film hardness was able to reach a B hardness level, and levels as high as $2 \mathrm{H}$. It can be seen that the varnish film hardness can be increased by infrared drying.

\section{Closed effect of waterborne coating $B$}

According to the four different processes for waterborne coating B, the wooden flooring substrates of pinnate pometia, Newtonia spp., and oak were finished, and the varnish film was tested. The tested results were shown in Table 4.

Table 4. Performance of the Varnish Film for Different Wood Species Depending on the Process Scheme of Finishing Technology

\begin{tabular}{|c|c|c|c|c|c|c|c|c|c|}
\hline \multirow[b]{2}{*}{ Process } & \multicolumn{3}{|c|}{ Pinnate pometia } & \multicolumn{3}{|c|}{ Newtonia spp. } & \multicolumn{3}{|c|}{ Oak } \\
\hline & 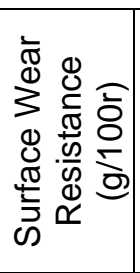 & 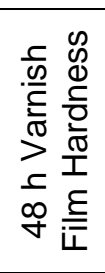 & 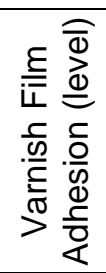 & 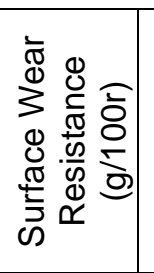 & 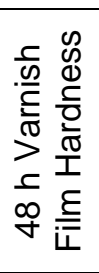 & 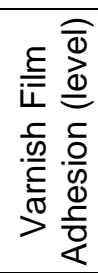 & 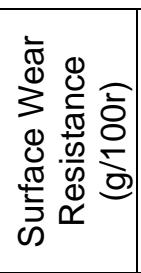 & 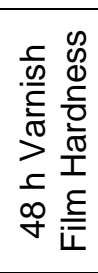 & 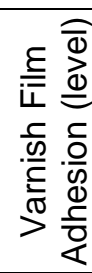 \\
\hline $\begin{array}{c}\text { Process } \\
1\end{array}$ & 0.15 & $2 \mathrm{H}$ & 0 & 0.14 & $2 \mathrm{H}$ & 0 & 0.10 & $2 \mathrm{H}$ & 0 \\
\hline $\begin{array}{c}\text { Process } \\
2 \\
\end{array}$ & 0.15 & B & 1 & 0.15 & B & 2 & 0.15 & $\mathrm{HB}$ & 1 \\
\hline $\begin{array}{c}\text { Process } \\
3\end{array}$ & 0.18 & B & 0 & 0.16 & B & 0 & 0.15 & $\mathrm{H}$ & 0 \\
\hline $\begin{array}{c}\text { Process } \\
4\end{array}$ & 0.18 & $3 B$ & 2 & 0.13 & B & 2 & 0.13 & $2 \mathrm{~B}$ & 2 \\
\hline
\end{tabular}

The varnish film hardness of the wooden flooring produced via Process 2 and 4 with UV curing was $3 \mathrm{~B}$ to HB. The varnish film hardness of the wooden flooring produced via Process 1 and 3 with infrared drying and UV curing was B to $2 \mathrm{H}$. In particular, the varnish film hardness of Process 1 reached a hardness level of $2 \mathrm{H}$ and was relatively stable. It was seen that the key to ensuring a high varnish film hardness was the coating amount and infrared drying. By consulting the literature, it can be seen that Ao et al. (2009) drew the same conclusion in their study of the effect of waterborne UV-cured coatings on the varnish film hardness of wooden flooring. According to the different properties of coating, different finishing schemes were formulated. The experimental results found that the 
hardness and wear resistance of the varnish film could be improved by adding infrared drying to the finishing process.

\section{Closed effect of waterborne coating $C$}

According to the four different processes for waterborne coating $\mathrm{C}$, the wooden flooring substrates of toothed oak, Robinia, and walnut were finished, and the varnish film was tested. The tested results were shown in Table 5.

Table 5. Performance of the Varnish Film Depending on Wood Species and the Process Scheme of Finishing Technology

\begin{tabular}{|c|c|c|c|c|c|}
\hline Species & Process & $\begin{array}{l}\text { Varnish } \\
\text { Film } \\
\text { Hardness }\end{array}$ & $\begin{array}{l}\text { Scratch } \\
\text { Hardness }\end{array}$ & $\begin{array}{l}\text { Varnish } \\
\text { Film } \\
\text { Adhesion } \\
\text { (level) }\end{array}$ & $\begin{array}{l}\text { Surface Wear Resistance } \\
\text { (g/100r) }\end{array}$ \\
\hline $\begin{array}{l}\text { Toothed } \\
\text { oak }\end{array}$ & $\begin{array}{c}\text { Process } \\
1 \\
\end{array}$ & $\mathrm{H}$ & $3 \mathrm{H}$ & 1 & $\begin{array}{c}0.06 \text { (varnish film remains on } \\
\text { the surface) }\end{array}$ \\
\hline $\begin{array}{l}\text { Toothed } \\
\text { oak }\end{array}$ & $\begin{array}{l}\text { Process } \\
2\end{array}$ & $\mathrm{H}$ & $4 \mathrm{H}$ & 1 & $\begin{array}{c}0.06 \text { (varnish film remains on } \\
\text { the surface) }\end{array}$ \\
\hline $\begin{array}{l}\text { Toothed } \\
\text { oak }\end{array}$ & $\begin{array}{c}\text { Process } \\
3\end{array}$ & $\mathrm{H}$ & $3 \mathrm{H}$ & 1 & $\begin{array}{c}0.05 \text { (varnish film remains on } \\
\text { the surface) }\end{array}$ \\
\hline Robinia & $\begin{array}{c}\text { Process } \\
1\end{array}$ & $\mathrm{HB}$ & $4 \mathrm{H}$ & 2 & $\begin{array}{c}0.06 \text { (varnish film remains on } \\
\text { the surface) }\end{array}$ \\
\hline Robinia & $\begin{array}{l}\text { Process } \\
2 \\
\end{array}$ & $\mathrm{HB}$ & $3 \mathrm{H}$ & 2 & $\begin{array}{c}0.05 \text { (varnish film remains on } \\
\text { the surface) }\end{array}$ \\
\hline Robinia & $\begin{array}{c}\text { Process } \\
3 \\
\end{array}$ & $2 \mathrm{H}$ & $3 \mathrm{H}$ & 2 & $\begin{array}{c}0.06 \text { (varnish film remains on } \\
\text { the surface) }\end{array}$ \\
\hline Walnut & $\begin{array}{c}\text { Process } \\
1 \\
\end{array}$ & $\mathrm{H}$ & $4 \mathrm{H}$ & 1 & $\begin{array}{c}0.06 \text { (varnish film remains on } \\
\text { the surface) }\end{array}$ \\
\hline Walnut & $\begin{array}{l}\text { Process } \\
2\end{array}$ & $\mathrm{H}$ & $4 \mathrm{H}$ & 1 & $\begin{array}{c}0.07 \text { (varnish film remains on } \\
\text { the surface) }\end{array}$ \\
\hline Walnut & $\begin{array}{c}\text { Process } \\
3 \\
\end{array}$ & $\mathrm{H}$ & $4 \mathrm{H}$ & 1 & $\begin{array}{c}0.06 \text { (varnish film remains on } \\
\text { the surface) }\end{array}$ \\
\hline
\end{tabular}

It can be seen from Table 4 that the hardness, adhesion, and surface wear resistance of the varnish film met the standard requirements when waterborne UV coating $\mathrm{C}$ with a high solid content consisting of a waterborne UV primer and water UV topcoat was used to finish the wooden flooring. However, the hardness, adhesion, and surface wear resistance of the varnish film were not remarkably improved by replacing the waterborne high-definition primer with a waterborne UV harden primer. On the contrary, in terms of varnish film appearance, the permeability was obviously affected, and the performance of the wooden flooring finished via Process 1 was even better.

\section{Effects of a Waterborne Coating on Wooden Flooring}

According to the experimental results, the process and parameters were screened. Among the opening effects of low solid content waterborne coatings, Process 3 was selected as the preferred scheme to produce the waterborne UV coating A for wooden flooring. Among the closed effects of high solid content waterborne coatings, Process 1 was selected as the preferred scheme to produce the waterborne UV coating $\mathrm{C}$ for wooden flooring. The relevant performance indexes of the wooden flooring were tested a thirdparty institution. The technology requirement of Q/YFL standard 0035-2018 (2018) and 
results of experiment are shown in Table 6. The varnish film hardness, surface wear resistance, surface pollution resistance, TVOC, and soluble heavy metal content were all in accordance with their standards, which suggested that the waterborne coating developed in this study could be used on wooden flooring.

Table 6. Test Results of the Performance Indexes of the Waterborne Coated Wooden Flooring

\begin{tabular}{|c|c|c|c|c|}
\hline \multicolumn{2}{|c|}{ Testing Items } & $\begin{array}{l}\text { Technology } \\
\text { Requirement }\end{array}$ & $\begin{array}{c}\text { Results of Low Solid } \\
\text { Content Water-based } \\
\text { Coating }\end{array}$ & $\begin{array}{c}\text { Results of High Solid } \\
\text { Content Water-based } \\
\text { Coating }\end{array}$ \\
\hline \multicolumn{2}{|c|}{$\begin{array}{c}\text { Varnish film adhesion } \\
\text { (level) }\end{array}$} & $\leq 2$ & 0 & 1 \\
\hline \multicolumn{2}{|c|}{$\begin{array}{c}\text { Surface wear } \\
\text { resistance }(\mathrm{g} / 100 \mathrm{r})\end{array}$} & $\begin{array}{l}\leq 0.15 \text { (varnish film } \\
\text { is not worn out) }\end{array}$ & $\begin{array}{c}0.10 \text { (varnish film is } \\
\text { not worn out) }\end{array}$ & $\begin{array}{l}0.05 \text { (varnish film is } \\
\text { not worn out) }\end{array}$ \\
\hline \multicolumn{2}{|c|}{ Varnish film hardness } & $\geq \mathrm{HB}$ & $2 \mathrm{H}$ & $5 \mathrm{H}$ \\
\hline \multicolumn{2}{|c|}{$\begin{array}{l}\text { Surface contamination } \\
\text { resistance }\end{array}$} & No traces of debris & No traces of debris & No traces of debris \\
\hline \multirow{4}{*}{$\begin{array}{c}72 \mathrm{~h} \text { VOC } \\
\left(\mu \mathrm{g} / \mathrm{m}^{3}\right)\end{array}$} & Toluene & $\leq 20$ & 4.75 & 3.35 \\
\hline & Xylene & $\leq 20$ & 2.8 & 0.86 \\
\hline & Benzene & $\leq 10$ & 8.1 & 0.86 \\
\hline & TVOC & $\leq 400$ & 41.96 & 120.14 \\
\hline \multicolumn{2}{|c|}{ Soluble $\mathrm{Pb}(\mathrm{mg} / \mathrm{kg})$} & $\leq 45$ & 0.06 & 0.03 \\
\hline \multicolumn{2}{|c|}{ Soluble Cd $(\mathrm{mg} / \mathrm{kg})$} & $\leq 37$ & 0.06 & 0.06 \\
\hline \multicolumn{2}{|c|}{ Soluble $\mathrm{Cr}(\mathrm{mg} / \mathrm{kg})$} & $\leq 30$ & 0.34 & 0.11 \\
\hline \multicolumn{2}{|c|}{ Soluble $\mathrm{Hg}(\mathrm{mg} / \mathrm{kg})$} & $\leq 30$ & 0.02 & 0.02 \\
\hline
\end{tabular}

\section{CONCLUSIONS}

1. Due to its excellent appearance and performance, waterborne coated wooden flooring has become the primary choice of consumers, as well as being a green product that meets the requirements of the coating industry promoted by China. In this paper, by screening tree species and choosing different process flows for the finishing and drying methods, two types of waterborne coated wooden floorings, with the effects of opening and closed were manufactured, and the performance of the varnish film was tested. The various tested performance indexes met the requirements of the provided standards.

2. In the process of experimentation, the adhesion, surface wear resistance, and hardness of the varnish film of low solid content water coating can reach respectively 0 level, $0.10 \mathrm{~g} / 100 \mathrm{r}$, and $2 \mathrm{H}$. The adhesion, surface wear resistance, and hardness of the varnish film of high solid content water coating can reach respectively 1 level, $0.05 \mathrm{~g} / 100 \mathrm{r}$ and $5 \mathrm{H}$, and the test results of surface contamination of two types waterborne coatings were excellent. At the same time, the detection of the VOC (toluene, xylene, benzene, TVOC) and soluble $\mathrm{Pb}, \mathrm{Cd}, \mathrm{Cr}$, and $\mathrm{Hg}$ were far less than the standard value.

3. In practice, wood chemical coloring technology and Grace technology were applied to waterborne coated wooden flooring, which not only enriches the color of the product, but also helps to highlight the effects of opening finishes. Based on these, a waterborne UV coated wooden flooring production line was established to provide a demonstration effect for the research and development of waterborne coated wooden flooring. Because the development and application research of waterborne UV coated wooden flooring products are still in the initial stage, it is necessary to continue to find problems in the usage process and provide technical follow-up in a timely manner. 


\section{ACKNOWLEDGMENTS}

The authors are grateful for the support of the National Key R\&D Program of China (Grant No. 2017YFD0601104).

\section{REFERENCES CITED}

Ao, J., Pan, J., Lu, X., Gao, S., Gui, C., and Pang, X. (2019). "Discussion on the application of waterborne UV curing coating on wood flooring," China Wood-Based Panels 26(3), 11-15.

Bongiovanni, R., Montefusco, F., Priola, A., Macchioni, N., Lazzeri, S., Sozzi, L., and Ameduri, B. (2002). "High performance UV-cured coatings for wood protection," Progress in Organic Coatings 45(4), 359-363. DOI:10.1016/S0300-9440(02)00119-4

Challener, C. (2015). "Trends in interior wood coatings: Tracking the shift from solvent to waterborne and UV," (https://www.paint.org/coatingstech-magazine/articles/ trends-in-interior-wood-coatings-tracking-the-shift-from-solvent-to-waterborne-anduv/), September 22, 2020.

Cai, Z., Zhu, H., Wang, P., Wu, C., Gao, W., Mu, J., and Wei, S. (2020). "Performance optimization of UV curable waterborne polyurethane acrylate wood coatings modified by castor oil," China Forestry Science and Technology 5(03), 89-95.

Eva, T. R., Berta, V. S., Makoto, N., Steven, R., and Adam, M. (2020). "High-performance: Waterborne wood floor coatings," Paint \& Coatings Industry 36(1), 32-34.

Feng, X., Jiang, X., and Wu, Z. (2020). "Current situation and development trend analysis of the surface decoration of wood furniture," Furniture 41(2), 12-15, 33.

GB/T 18103-2013 (2013). "Engineered wood flooring," Standardization Administration of China, Beijing, China.

GB/T 35601-2017 (2017). “Green product assessment--Wood-based panels and wooden flooring," Standardization Administration of China, Beijing, China.

Huang, Y., Zhao, C., Feng, Q., and Chang, X. (2018). "Coating process of acrylic acid water-based paint and its effect on film properties," China Forest Products Industry 45(1), 24-26, 34.

Hwang, H.-D., Moon, J.-I., Choi, J.-H., Kim, H.-J., Kim, S. D., and Park, J. C. (2009). "Effect of water drying conditions on the surface property and morphology of waterborne UV-curable coatings for engineered flooring," Journal of Industrial and Engineering Chemistry 15(3), 381-387. DOI: 10.1016/j.jiec.2008.11.002

Li, R., Fang, L., Xu, W., Xiong, X., and Wang, X. A. (2019). "Effect of laser irradiation on the surface wettability of poplar wood," Science of Advanced Materials 11(5), 655-660. DOI: 10.1166/sam.2019.3450

Li, R., Xu, W., Wang, X. A., and Wang, C. (2018). "Modeling and predicting of the color changes of wood surface during CO2 laser modification," Journal of Cleaner Production 183, 818-823. DOI: 10.1016/j.jclepro.2018.02.194

Li, Y., and Shu, Z. (2007). "Research and development of UV-curable waterborne floor primer," Modern Paint and Finishing 11, 14-16.

Lin, X., Su, J., Zhang, X., Tan, Z., Wang, C., and Wei, S. (2019). "Synthesis of UV cured waterborne polyacrylate wood coatings modified by silica sol," China Forestry Science and Technology 4(06), 170-176.

LY/T 1859-2009 (2009). “Antique style flooring," Standardization Administration of 
China, Beijing, China.

Pánek, M., Dvořák, O., Oberhofnerová, E., Šimůnková, K., and Zeidler, A. (2019). "Effectiveness of two different hydrophobic topcoats for increasing of durability of exterior coating systems on oak wood," Coatings 9(5), 1-13. DOI: $10.3390 /$ coatings 9050280

Q/YFL 0035-2018 (2018). "Wooden floorings coated with water-borne UV varnishes," Standardization Administration of China, Beijing, China.

Shen, H., Ma, H., and Xiao, G. (2010). "Discussion on water-borne coatings filmforming mechanism," China Coatings 25(6), 24-27, 44.

Sun, Y., Wang, C., Wu, Y., Zuo, J., and Zhan, X. (2020). "Effect of nano-boron carbide on the properties of waterborne polyurethane wood coatings," China Forestry Science and Technology 5(04), 181-185.

Spilman, G. E., Moore, S., and Marshall, S. J. (2018). "Sustainable, low-emissions, highperformance polyols for wood floor coatings," CoatingsTech 15(10), 34-43.

Tang, X., Li, X., Chen, H., and Zhang, J. (2003). "Study on water soluble prepolymer UV cure and its coating film behaviour," Journal of Hunan University (Natural Science Edition) 30(4), 36-39.

Tao, X., Mao, Z. N., Xu, W., Chen, C. H., and Tang, X. L. (2019). "Effect of antique painting technology on film roughness of modified poplar," China Forest Products Industry 46(06), 33-36.

Wilfried, S., Margret, G., Brigitte, K., and Ute, F. (2004). "Wax additives in aqueous parquet lacquers and printing inks," Shanghai Coatings 42(z1), 19-22.

Wu, H. G., Long, L., Xu, J. F., Chen, M. G., Liu, R., and Chang, H. Y. (2019). "Effect of UV-waterborne wood coating weight on film drying time and film performance," China Wood Industry 33(5), 7-10.

Xiong, X., Guo, W., Fang, L., Zhang, M., Wu, Z., Lu, R., and Miyakoshi, T. (2017). "Current state and development trend of Chinese furniture industry," Journal of Wood Science 63(5), 433-444.

Xiong, X., and Wu, Z. (2018). "Present situation and development trend of intelligent manufacturing in home furnishing industry," Journal of Forestry Engineering 3(6), 11-18.

Xiong, X., Liu, H., Zhu, Q., Bao, Y., and Wu, Z. (2018a). "Development of the customized home furnishing industry chain," China Wood Industry 32(2), 18-22, 27.

Xiong, X., Yuan, Y., Fang. L., Liu, H., and Wu, Z. (2018b). "Status and development trends of intelligent manufacturing in china's furnishings industry," Forest Products Journal 68(3), 328-336.

Xiong, X., and Ma, Q., Yuan, Y., Wu, Z., and Zhang, M. (2020). "Current situation and key manufacturing considerations of green furniture in china: A review," Journal of Cleaner Production 267, 1-35. DOI: 10.1016/j.jclepro.2020.121957

Xu, W., Fang, X., Han, J., Wu, Z., and Zhang, J. (2020). "Effect of coating thickness on sound absorption property of four wood species commonly used for piano soundboards," Wood and Fiber Science 52(1), 28-43. DOI: 10.22382/wfs-2020-004

Yan, X., Qian, X., and Bao, W. (2020a). "Effect of glass fiber powder on the properties of the waterborne coatings with color changing ink on the Chinese fir surface," China Forestry Science and Technology 5(03), 169-174.

Yan, X., Wang, L., and Qian, X. (2020b). "Influence of the PVC of glass fiber powder on the properties of a thermochromic waterborne coating for Chinese fir boards," Coatings 10(6), 588-603. DOI: 10.3390/coatings10060588 
Yan, X., Cai, Y., Guo, W., Yang, R., Qian, X., Pan, P., and Xu, W. (2019). "Preparation of urea-formaldehyde@epoxy resin microcapsule and its effect on waterborne wood coatings," China Forestry Science and Technology 4(01), 160-164.

Zhu, W., Wu, Y., Yu, C., Cao, K., and Wu, Z. (2016). "The modification of lacquer and its application in furniture spraying process," Paint \& Coatings Industry 46(10), 8387.

Article submitted: October 15, 2020; Peer review completed: December 5, 2020; Revised version received and accepted: December 9, 2020; Published: December 18, 2020.

DOI: 10.15376/biores.16.1.1101-1114 